Biocontrol Science, 2018, Vol. 23, No. 2, 81-83

Note

\title{
Anti-Ice Nucleation Activities of Tyrosine Peptide
}

\author{
ERI TAGAWA ${ }^{1}$, MAYUMI URA ${ }^{1}$, ERI NAKATSUKA ${ }^{2}$, YOSHIAKI HIRANO², \\ AND HIDEHISA KAWAHARA ${ }^{1 *}$ \\ ${ }^{1}$ Department of Life Science and Biotechnology, Kansai University, \\ 3-3-35 Yamate-cho, Suita-shi, Osaka 564-8680, Japan \\ ${ }^{2}$ Department of Chemistry and Materials Engineering, Kansai University, \\ 3-3-35 Yamate-cho, Suita-shi, Osaka 564-8680, Japan \\ Received 12 June, 2017/Accepted 23 September, 2017
}

\begin{abstract}
We investigated whether trimers of serine, threonine, tyrosine, and phenylalanine which may interact with water molecules and ice, show anti-ice nucleation activity. Only tyrosine trimer had high levels of anti-ice nucleation activity $\left(10.10 \pm 0.74^{\circ} \mathrm{C}\right)$ at a final concentration of $0.2 \mathrm{mM}$. This was constant at an activity of $2.0^{\circ} \mathrm{C}$ between the $0.01-0.1 \mathrm{mM}$ concentrations, and rapidly increased at $0.1 \mathrm{mM}$ or more. At the final concentration of $0.2 \mathrm{mM}$ or more, the activity of the tyrosine trimer was almost constant (from $9.2^{\circ} \mathrm{C}$ to $10.2^{\circ} \mathrm{C}$ ). Although it is lower than the activity against silver iodide, the tyrosine trimer showed an effect on the activity of the ice nucleating bacteria. This is the first report that revealed that trimer of amino acid, especially tyrosine has the supercooling-facilitating activity.
\end{abstract}

Key words : Anti-ice nucleation activity / Tyrosine / Tripeptide.

Subzero winter temperatures pose a significant challenge for the survival of organisms in temperate and polar region. One strategy of many organisms living in these areas is the use of a mechanism based on freezing point depression trough accumulation of cryoprotectants such as sugars and polyhydric alcohol (Storey 1983). Other strategies use a mechanism based in physical damage avoidance through production of antifreeze material and ice nucleators (DeVries 1988; Zacchariasen and Kristiansen 2000).

In subzero conditions, all organisms are exposed to conditions that necessitate the partial removal of water from the intracellular space in order to maintain the structure and function of the cell. Any significant deviation in the accessibility of water due to dehydration, desiccation or alteration of water's physical state, that is, from the aqueous phase to an ice crystal, will pose a severe threat to the normal function and survival of an organism (Beall 1983; Kawahara 2002). These ice control threats are alleviated by proteins involved in three different ice crystal formation processes. Various organisms containing some bacteria can counteract or minimize the

*Corresponding author. Tel: +81-6-6368-0832, Fax: +81-66388-8609, E-mail : kawahara (a)kansai-u.ac.jp deleterious effect of ice crystal formation in the intracellular and extracellular spaces. Ice nuclei can be formed by homogeneous (no particle present) or heterogeneous (particle-induced) nucleation in the first step. The formation of ice nuclei through heterogeneous ice nucleation is promoted by foreign particles, that is, silver iodide etc. that act as a ice nucleation activator. Various types of ice nucleation activators of biogenic origin are known to exist in plant bacteria, fungi, insects, plants and lichens (Gross et al 1988; Wolber 1993). Inhibitors of heterogeneous ice nucleation, which can favor supercooling, have been found in various organisms. These inhibitors containing polyphenol are known to exist in the xylem parenchyma cells of Katsura trees (Cercidiphyllum japonicum) (Kasuga et al 2007). Kawahara et al have also purified an anti-nucleating protein from Acinetobacter calcoaceticus $\mathrm{KINI}-1$, which was isolated from the camphor leaf (Kawahara et al 1996). Other ice crystalcontrolling materials, which can play a crucial role in the second step of ice formation, are antifreeze proteins, antifreeze glycoproteins and antifreeze glycolipids. The function of antifreeze protein (AFP) is to inhibit ice formation and ice crystal growth by suppressing the binding of water molecules to the ice crystal surface (Davies et al 2002). 
Amino acids involved in the expression of the activity of three different ice-regulating proteins are different, and the activity expression of ice nucleation protein and antifreeze protein is characterized. In the former, the tandem consensus octapeptide, Ala-Gly-Tyr-Gly-SerThr-Leu-Thr, of the central domain is hypothesized to form a $\beta$-helical fold secondary structure (GurianSherman and Lindow 1993). By this repetition of this octapeptide, the degree of hydrophobicity of the protein increases and becomes an ice core as an insoluble protein. In the latter, the antifreeze protein derived from insects with the highest activity has a repeating structure of the Tyrosine- $X$-Tyrosine (TXT) motif, and the hydroxyl group of threonine is hydrogen bonded to the water molecules of the ice crystals (Graether et al 2003). As the amino acid sequence of supercooling-facilitating (SCF) protein having the anti-ice nucleating activity remains unknown. Which amino acids are involved in the activity of SCF protein has not yet been clarified.

In this study, with reference to the TXT motif, the antiice nucleating activities of tripeptide of four amino acids having hydroxyl groups were investigated. Among four amino acids, SCF activity, anti-ice nucleating activity of tyrosine residue peptide was characterized. This is the first report that revealed that tripeptide of amino acid has SCF activity.

The trimers of serine, threonine and phenylalanine were purchased from Bachem Inc. (Bubendorf, Switzerland). The dimer, trimer, tetramer, pentamer and hexamer of tyrosine were prepared using the following synthesis method. Oligotyrosine $(n=3,4,5)$ were synthesized on Alko-PEG resin (Watanabe Chemical Industries, LTD) using manually standard Fmoc-protocol with 4-(4,6-Dimethoxy-1,3,5-triazin-2-yl) -4-methylmorpholinium Chloride (DMT-MM) activation procedure (Hioki et al 2004; Fields and Noble 1990; King et al 1990). The synthetic peptides were purified by RP-HPLC, and characterized by MALDI-TOF-MS.

The anti-ice nucleation activity was measured by a modified method of ice nucleating activity. The icenucleating temperature was measured with a freezing nucleus spectrometer (Thermoelectric cold plate model KM-1) (Vali 1971). That is, thirty drops, each of $10 \mu$, were placed on a temperature-controlled surface, and the temperature was lowered from $4{ }^{\circ} \mathrm{C}$ to $-20^{\circ} \mathrm{C}$ at a rate of $1.0^{\circ} \mathrm{C}$ per min. The temperature at which $50 \%$ of the drops froze was recorded $\left(T_{50}\right)$. The silver iodide suspension $(1 \mathrm{mg} / \mathrm{ml})$ of $90 \mu \mathrm{l}$ and the sample or distilled water of $10 \mu \mathrm{l}$ were mixed, and kept at room temperature for $30 \mathrm{~min}$. Before measuring this activity each sample was passed through a $0.45-\mu \mathrm{m}$ filter to remove small particles. The anti-ice nucleation activity was defined as the difference between the ice-nucleating temperature $\left(T_{50}\right)$ of sample and the distilled

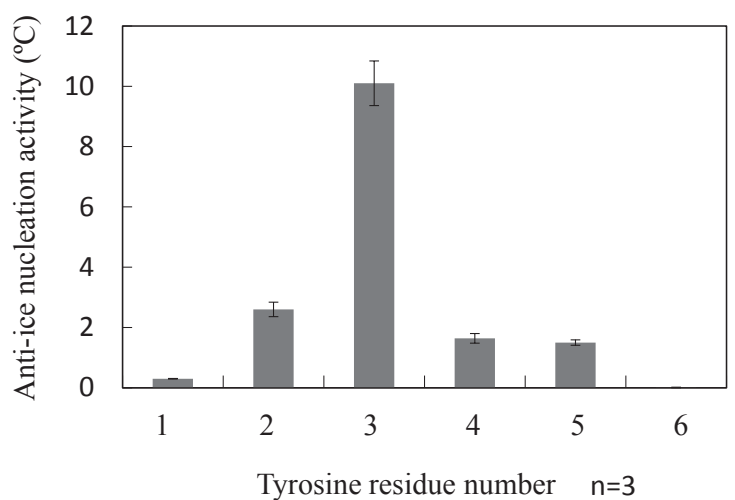

FIG. 1. The effect of tyrosine peptide number on the anti-ice nucleation activity.

water. All amino acids were prepared as $2 \mathrm{mM}$ aqueous solution and the anti-ice nucleation activity was measured at the final concentration of $0.2 \mathrm{mM}$. When it was insoluble in water, it was dissolved in dimethylfluoxide (DMSO).

On the examination of the specificity on anti-ice nucleation activity, silver iodide, 9-fluorenon, and two species of ice nucleating bacterium were used as the ice nuclei under the condition of suspension or solution. Pseudomonas fluorescens and P. syryngae were prepared with cell suspension, which were adjusted to an OD at $660 \mathrm{~nm}$ of 0.1 with $50 \mathrm{mM}$ potassium phosphate buffer $(\mathrm{pH} 7.0)$. The strain $\mathrm{KUIN}-1$ of $P$. fluorecsens was isolated by Obata et al (1987). The strain NBRC 3310 of $P$. syringae was originated from Biotechnology center of National Institute of Technology and Evaluation.

Data in the Figures were reported as the mean $\pm S D$. Differences in $P$ values that were $<0.05$ were considered significant.

The anti-ice nuclear activities of tyrosine, phenylalanine, serine, and threonine which have hydroxyl groups and possibly interact with ice and water molecules were investigated. Each activity of tyrosine, phenylalanine, serine, and threonine was $0.33 \pm 0.01,0.53 \pm 0.02$, $0.10 \pm 0.01$ and $0.13 \pm 0.01^{\circ} \mathrm{C}$, respectively. Among trimer of each amino acid, only the tyrosine trimer had high levels of anti-ice nucleation activity (10.10士 $0.74^{\circ} \mathrm{C}$ ) at a final concentration of $0.2 \mathrm{mM}$. Interestingly, the trimer of threonine showed $0.34^{\circ} \mathrm{C}$ that there was a higher ice nucleation activity than silver iodide. Next, the effect of peptide number of tyrosine on the anti-ice nucleation activity was examined. As shown in FIG.1, the tyrosine peptide with the highest activity was a trimer $\left(10.10 \pm 0.74^{\circ} \mathrm{C}\right)$, and it became abruptly abolished when it had a length longer than the trimer. Also, as a result of examining the effect of its concentration on the ice nucleation activity of silver iodide, at the final 
concentration of $0.2 \mathrm{mM}$ or more, the anti-ice nuclear activity of the tyrosine trimer was almost constant (from $9.2^{\circ} \mathrm{C}$ to $10.2^{\circ} \mathrm{C}$ ). This constant value may be the saturated binding state of the trimer to silver iodide.

Furthermore, this activity was constant at an activity of $2.0^{\circ} \mathrm{C}$ between the 0.01-0.1 mM concentrations, and rapidly increased at $0.1 \mathrm{mM}$ or more. This phenomenon is almost the same as the pattern of thermal hysteresis activity of antifreeze proteins. That is, the activity is increased by the amount of antifreeze protein bound to the surface of ice crystals. However, this activity at a final concentration of $0.2 \mathrm{mM}$ was higher than that of the reported compound, pelargonidin 3-O-glucopyranoside $\left(7.1^{\circ} \mathrm{C}\right.$ ) (Kuwabata et al 2012). In addition to silver iodide, it has been reported that supercooling promoting substances reported so far have an effect on the ice nucleation activity of ice nucleating bacteria. This effect suggests possibility as a frost damage control agent. Next, against the ice nucleators from ice nucleating bacteria, the anti-ice nucleating activity of tyrosine trimer $(0.2 \mathrm{mM})$ was examined. The ice nucleation activity of P. fluorescens $\mathrm{KUIN}-1$ was depressed $\left(1.90 \pm 0.32^{\circ} \mathrm{C}\right)$. Also, the anti-ice nucleation activity against $P$. syringae NBRC3310 was $0.34 \pm 0.01^{\circ} \mathrm{C}$. Differences in the effect of tyrosine trimer predict that the difference in ice nucleating bacteria is due to differences in the size of ice nucleating proteins produced by ice nucleated bacteria. Also, Kobashigawa et al (2005) was shown that the recombinant 97 residues polypeptide corresponding to the sequence Tyr176 to Gly273 of ice nucleation protein from Pseudomonas syringae has the ability to shape an ice crystal, whose morphology was highly similar to that the hexagonal bi- pyramid form generally identified antifreeze proteins. The fact that the expression of anti-ice nuclear activity and lack of ice nucleation activity is influenced by the presence of tyrosine residues may be an important finding for the design of macromolecular compounds with ice regulation.

In the present study, we clarified for the first time that tyrosine trimer has an extremely high anti-ice nucleation activity. It is predicted that the tertiary structure of the tyrosine trimer forms a pocket where foreign substances are easy to trap and that the hydroxyl group and amino group on the opposite side may be easily hydrated with water molecules. Since the structure of the tyrosine trimer capable of trapping the foreign substance like silver iodide is a factor of high activity, there is a possibility that tyrosine peptides with the structure of trimer or higher might not maintain this optimum shape. Also, since tyrosine trimer shows high activity against inorganic iodide which is an inorganic substance, tyrosine trimer can be expected to be applied to frost adhesion inhibitors and the like as a frost damage control agent. We plan to continue studying the mechanism of tyrosine trimer activity development and its applications for antifrost adhesion agents.

\section{REFFERENCE}

Beall, P. T. (1983) States of water in biological systems. Int. J Biochem. Cell Biol., 20, 324-334.

Davies, P. L., Baardsnes, J, Kuiper, M. J., and Walker, V. K. (2002) Structure and function of antifreeze proteins. Phil. Trans. R. Soc. Lond. B., 357, 927-935.

DeVries, A. L. (1988) The role of antifreeze glycopeptide and peptides in the freezing avoidance of Antarctic fishes. Comp. Biochem. And Physiol. B, 90, 611-621.

Fields, G. B., and Noble, R. L. (1990) Solid phase peptide synthesis utilizing 9-fluorenylmethoxycarbonyl amino acids. Int. J. Pept. Protein. Res., 35, 161-214.

Graether, S. P., Gragné, S. M., Spyracopoulos, L., Jia, Z., Davies, P. L., and Sykes, B. D. (2003) Spruce budworm antifreeze protein: changes in structure and dynamics at low temperature. J. Mol. Biol., 327, 1155-1168.

Gross, D. C., Proebsting, E. L., and Maccrindle-Zimmenrman, H. (1988) Development, distribution, and characteristics of intrinsic, nonbacterial ice nuclei in prunus wood. Plant Physiol., 88, 915-922.

Gurian-Sherman, D, and Lindow, S. E. (1993) Bacterial ice nucleation: significance and molecular basis. FASEB J., 7, 1338-1343.

Hioki, K., Kobayashi, K., Ohkihara, R., Tani, S., Kunishima, M. (2004) Preparation of Weinreb Amides Using 4-(4,6Dimethoxy-1,3,5-triazin-2-yl)-4-methylmorpholinium Chloride (DMT-MM). Chem. Pharm. Bull., 52, 470-472.

Kasuga, J., Mizuno, K., Arakawa, K., and Fujikawa, S. (2007) Anti-ice nucleation activity in xylem extracts from trees that contain deep supercooling xylem parenchyma cells. Cryobiology, 55, 305-314.

Kawahara, H., Nagae, I., and Obata, H. Purification and characterization of a new anti-nucleating protein isolated from Acinetobacter calcoaceticus KINI-1. (1996) Biocotrol Sci., 1, 11-17.

Kawahara, H. (2002) The structure and function of ice crystalcontrolling proteins from bacteria. J. Biosci. Bioeng., 94, 492496.

King, D. S., Fields, C. G., and Fields, G. B. (1990) A cleavage method which minimizes side reactions following Fmoc solid phase peptide synthesis. Int. J. Pept. Protein. Res., 36, 255266.

Kobashigawa, Y., Nishiyama, Y., Miura, K., Ohgiya, S., Miura, A., and Tsuda, S. (2005) A part of ice nucleation protein exhibits the ice-binding ability. FEBS Lett., 579, 1493-1497.

Kuwabara, C., Kasuga, J., Wang, D., Fukushi, Y., Arakawa, K., Koyama, T., Inada, T., and Fujikawa, S. (2012) Freezing activities of flavonoids in solutions containing different ice nucleators, Cryobiology, 64, 279-285.

Obarta, H., Saeki, Y., Tanishita, J., Tokuyama, T., Hori, H., and Higashi, H. (1987) Identification of an ice-nucleating bacterium KUIN-1 in Pseudomonas fluorescens and its nucleation properties. Agric. Biol. Chem., 51, 1761-1766.

Storey, K .B. (1983) Metabolism and bound water in overwintering insects. Cryobiology, 20, 365-379.

Vali, G. (1971) Quantitative evaluation of experimental results on the heterogeneous freezing nucleation of supercooled liquid. J. Atom. Sci., 28, 402-409.

Wolber, P. K. (1993) Bacterial ice nucleation. Adv. Microb. Physiol., 34, 203-237.

Zacchariasen, K. E., and Kristiansen, E. (2000) Ice nucleation and antinucelation in nature. Cryobiology, 41, 257-259. 